\title{
The Interactive Digital Entertainment (IDE) Unification Framework: Creating a taxonomy of IDE and Lifestyle Computing
}

\begin{tabular}{|c|c|c|}
\hline Greg Moody & Taylor Wells & Paul Benjamin Lowry \\
Information Systems & Information Systems & Information Systems \\
Department & Department & Department \\
University of Pittsburg & Indiana University & Brigham Young University \\
gregmoody100@hotmail.com & taylor.m.wells@gmail.com & Paul.Lowry@BYU.edu \\
\hline
\end{tabular}

\begin{abstract}
In this paper, we create a taxonomy of interactive digital entertainment (IDE), which can be used to guide future research in IDE and direct the design of interactive entertainment. We start by defining and explaining the differences between IDE and lifestyle computing. We then review the major taxonomies on gaming that can illuminate research and practice with IDE. Given this review, we propose an overarching taxonomy called the IDE Unification Framework. Based on this framework, we then propose promising areas for future research.

\section{Introduction}

Whereas original computing devices were only meant to aid in performing specific functions, new devices and software to support them have created new ways in which people interact daily with technology. This "everyday computing" or personal computing [1] is most visible in the area of leisure and enjoyment in which "entertainment systems"[2] and "entertainment computing" [3] have become commonplace. The phenomenal growth of these technologies has opened a stream of academic research related to the use and influence of these technologies that is currently undefined and understudied. We call these areas of research interactive digital entertainment (IDE) and lifestyle computing (LC). Because IDE and LC technologies focus on personal or non-business uses for technology, these systems have also been classified as hedonic systems [4].

IDE and LC overlap in some research areas; however, it is important to understand their separate goals. IDE technologies are digital systems that have an express purpose of providing entertainment for the user. LC differs from IDE in that the purpose of an LC technology is to augment one's ability to perform tasks outside the professional realm. Table 1 provides a summary of the differences between IDE and LC technologies.

It is critical to create taxonomies for IDE and LC research, because these are emerging research areas
\end{abstract}

and taxonomies can provide a common language to communicate research. Researchers have noted that a lack of clear categorization or ambiguous constructs can affect the quality of research [6].

In this paper, we provide organization to the emerging and fragmented research on IDE and LC that future research can build upon. First, we define the terms IDE and LC. Second, we briefly review and define some of the established areas of academic research in interactive digital entertainment and lifestyle computing. Third, we review several academic taxonomies of gaming and provide a new unified framework that synthesizes these taxonomies. Finally, we point out potential areas of future research.

\section{IDE vs. LC}

Fundamental to an understanding of IDE are working definitions of interactivity and entertainment. Liu and Shrum [7] define interactivity as a two-way communication and exchange in which two or more entities send related messages to each other [7]. Interactive devices modify responses to users based upon the input or message they receive from its user. The process of adapting output based upon incoming messages is characteristic of interactivity [8].

Entertainment is a complex, multifaceted construct that is difficult to define [9]. Vorderer [9] defined entertainment in the following way: "It's an experience that helps media users to cope with their everyday life. For some, it's pleasure seeking in boring situations or compensation in burdening situations; for others it's compensation in a depriving situation, fulfillment of needs in unsatisfactory situations, and self-enhancement or even self-realization when they are - for whatever reason - ready for it" (p. 258).

Most definitions of entertainment are in terms of constructs such as enjoyment, interactivity, presence, competition, involvement, pleasure, play, etc. For IDE we are particularly interested in the context of interactive media. Thus, we define interactive entertainment as the enjoyment that results from one's involvement with an interactive technology that 
enables an activity designed to produce enjoyment. Entertainment does not have to be the only function of the system, but simply an outcome from using the system. Thus, a video game console would be categorized as an IDE system, as would an online computer game or interactive Television (iTV). However, products such as board games would not be classified as IDE systems as they do not involve digital media. Traditional movies, even if digitized, would not be classified as IDE systems, because users cannot affect the output of traditional movies.

In contrast, LC is a phenomenon in which computing devices are moving outside the office and into people's personal lives. It has also been called "household technology" [10, 11] or "ubiquitous computing in the home" [12]. Thelander [13] describes lifestyle computing as "the application of advanced computer technology to mass-marketed consumer devices" (p. 25). We expand upon this definition to include the operation of these devices. Thus, we define lifestyle computing as the use of digital systems to augment the ability to perform personal tasks outside of professional work. Research in this area includes the use of social networking, wearable computing, home automation, and personal electronic devices such as PDAs, cell phones, or GPS units.

Whereas the primary purpose of this paper is to focus on IDE, this area of research cannot be discussed without first comparing and contrasting it to LC. Both IDE and LC find their theoretical bases from several fields and encompass many research areas. IDE has grown to become a multi-billion dollar, worldwide industry with game sales alone passing $\$ 7$ billion [5]. Despite this growth, little scientific research has been performed to define and stimulate this emerging area of computing research. With some exceptions, much of the research that has been conducted on IDE and/or LC is atheoretical and/or not empirically validated. To understand and influence the impact of IDE, more rigorous theoretical and empirical research must be performed.

IDE and LC are fundamentally different from many other technologies in that they are meant to entertain and augment one's personal life, rather than to raise one's efficiency or proficiency with a given business-related task. Crabtree et al. [12] point out that the familiar business goals of efficiency or productivity through technology may not be appropriate for lifestyle computing; nevertheless, the goals of LC are to supplement a user's performance in or achievement of personal tasks.

For example, Blizzard Entertainment's World of Warcraft ${ }^{\mathrm{TM}}$ game, which is played online, falls into the category of IDE. The user interacts with the program on the computer in an effort to be entertained. The game allows many users from all over the world to interact in a virtual world where each user assumes a created character. One's character can develop, grow, and interact with other virtual characters in this virtual realm. Users are able to socialize and meet other users and experience a high degree of sociality in this environment for the purpose of enjoyment and entertainment.

In contrast, Facebook.com ${ }^{\mathrm{TM}}$, a social networking online website, is an example of an LC technology. Facebook.com allows user an increased ability to virtually meet other users no matter the geographic distance. Although its users also experience a high degree of sociality with other Facebook.com users, unlike players of World of Warcraft, users of Facebook.com are actively engaging with other users instead of the world that is created by the program. The two differ in their virtuality, or the level in which the users interact with users or the virtual world of the program/game. Table 1 provides a summary of the differences between IDE and LC technologies.

Table 1. Summary of Differences between IDE and LC Systems

\begin{tabular}{|l|l|l|}
\hline \multicolumn{2}{|l|}{$\begin{array}{l}\text { Interactive Digital } \\
\text { Entertainment } \\
\text { Systems }\end{array}$} & $\begin{array}{l}\text { Lifestyle Computing } \\
\text { Systems }\end{array}$ \\
\hline $\begin{array}{l}\text { Reality } \\
\text { focus }\end{array}$ & $\begin{array}{l}\text { Creating a } \\
\text { completely virtual } \\
\text { world to interact with } \\
\text { the user(s) }\end{array}$ & $\begin{array}{l}\text { Expanding or augmenting } \\
\text { the real-world of the user(s) }\end{array}$ \\
\hline $\begin{array}{l}\text { Main } \\
\text { purpose }\end{array}$ & $\begin{array}{l}\text { Providing } \\
\text { entertainment or } \\
\text { leisure for its user(s) }\end{array}$ & $\begin{array}{l}\text { Expanding or enhancing the } \\
\text { ability of a user to perform } \\
\text { personal tasks, and/or } \\
\text { interact with more users } \\
\text { than could be done without } \\
\text { the capabilities by the LC } \\
\text { system }\end{array}$ \\
\hline $\begin{array}{l}\text { Number } \\
\text { of users } \\
\text { involved }\end{array}$ & $\begin{array}{l}\text { Small numbers to } \\
\text { millions of users } \\
\text { interacting inside the } \\
\text { created world of the } \\
\text { game }\end{array}$ & $\begin{array}{l}\text { Can be one user performing } \\
\text { a personal task, or one user } \\
\text { interacting with a group of } \\
\text { users that can be very small } \\
\text { or number in the millions }\end{array}$ \\
\hline Org. & $\begin{array}{l}\text { Highly organized into } \\
\text { groups or identities }\end{array}$ & $\begin{array}{l}\text { Loosely organized, more } \\
\text { prone for ad hoc queries or } \\
\text { searches for users }\end{array}$ \\
\hline Control & Technology-centric & User-centric \\
\hline Other & $\begin{array}{l}\text { Most systems require } \\
\text { purchase or funds to } \\
\text { continue to use the } \\
\text { system }\end{array}$ & $\begin{array}{l}\text { Many systems are free of } \\
\text { charge and take advantage } \\
\text { of large network effects }\end{array}$ \\
\hline
\end{tabular}

To further build a taxonomy of IDE and LC, it is important to overview the main areas of personal computing, including: platform gaming, online gaming, virtual reality, interactive television, simulations, pervasive gaming, interactive storytelling, social networking, wearable computing, home 
automation, and personal electronic devices. We briefly introduce, describe, and define them in this section

\subsection{Platform Gaming}

We define platform gaming as an IDE system that uses a console to provide an operating system necessary to operate the game involving a user or users collocated in the same physical location. This type of gaming has experienced widespread use for over 30 years beginning with the commercial success of the Atari 2600 gaming system in the 1970s. With the passage of time, this area has expanded to include games from such areas as the Nintendo Entertainment System $^{\mathrm{TM}}$, Sony Playstation ${ }^{\mathrm{TM}}$, Microsoft $\mathrm{Xbox}^{\mathrm{TM}}$, numerous handheld gaming devices, the personal computer, and other devices. Non-traditional platform gaming consoles, such as cell phones, wrist watches, table-top gaming and BlackBerry ${ }^{\mathrm{TM}}$ devices, have also been extended to allow platform gaming.

The majority of platform games involve only one player using the gaming console and operating some controller that serves as an input device for the system. More advanced gaming systems allow a few more players to also play in the same game at the same time, provided that the additional user(s) are physically present and have access to an input device. Other systems are handheld and have input devices built into the actual console, or use keyboard/mouse-like devices.

All gaming within this environment is within the actual system operating the game. Input is gathered from the user(s) and is processed by the system. Output is displayed on either the system or some type of monitor to allow the user(s) to continue interacting with the system. Thus, the game is all incorporated in one location and one software platform.

\subsection{Online Gaming}

We define online gaming as any game that is played between users that are not physically located in the same physical location, using Internet protocols for all communications. The majority of these games are accomplished through the use of the Internet by various computer-based games or gaming consoles such as $\mathrm{Xbox}^{\mathrm{TM}}$ or Playstation ${ }^{\mathrm{TM}}$. One major area of online gaming that has received the majority of recent attention is massively multiplayer online gaming (MMOG, sometimes called MMORPG for role playing games). MMOGs are games that allow many players to join and collectively play a game. Many of these games are role-playing games that allow each user to create a fictitious identity and interact with other players while they explore the virtual world and improve their character. MMORPGs include such games as World of Warcraft ${ }^{\mathrm{TM}}$, Lineage ${ }^{\mathrm{TM}}$, Lineage II $^{\mathrm{TM}}$, RuneScape ${ }^{\mathrm{TM}}$, Everquest ${ }^{\mathrm{TM}}$ and Final Fantasy $\mathrm{XI}^{\mathrm{TM}}$.

\subsection{Virtual Reality}

Brooks [14] defines virtual reality as an experience "in which the user is effectively immersed in a responsive virtual world" (p. 16). This is accomplished by the use of special visual displays and user input devices. These augmented reality systems allow a user to enter a virtual world and interact with that world in a similar way that an individual interacts with objects and people in the real world. Many current virtual reality (VR) systems have been driven by a desire for entertainment and can be commonly found in theme parks $[15,16]$, however not all virtual reality relates to entertainment and may increasingly support LC. Virtual reality systems can be found in medical, military, educational, manufacturing, and other problem solving applications [15].Our focus is limited to IDE virtual reality. As virtual reality is largely limited by advances in the hardware used to produce the immersive environment, much of the academic research has investigated performance improvements of VR devices. Other research has looked at the use of VR, the usability of VR interfaces [17], etc.

Currently, virtual reality depends on relatively expensive equipment to allow a user to enter and interact with a virtual world; as a result, it is a limited part of mainstream IDE and LC. As costs for equipment decrease, it is anticipated that virtual reality systems will become more commonplace and used in IDE or LC systems by many individuals.

\subsection{Inter active Television}

We define interactive television as a system that allows a television user the opportunity to direct and exchange information with the television that will change the viewed content on the screen. Interactive television allows additional features to the viewer such as: time-shifted program viewing, bidirectional feedback (e.g., voting), subtitles or interactive games that serve to enrich the viewing experience [18]. Interactive television (iTV) has found some form of adoptions in Europe with several TV stations/providers that provide iTV programs and/or capabilities for their viewers/subscribers [18, 19]. iTV research has been limited to demographics, content, and technical issues that are presented in a conference devoted to iTV in Europe held annually. Like virtual reality, not all interactive television is for entertainment purposes, but our focus is only on entertainment. 


\subsection{Simulation Games}

We define a simulation as a system that allows a user to experience a real-world scenario, device, or situation in a virtual world created for the express purpose of experiencing the scenario, device, or situation. As such, a simulation game includes a simulation with the purpose of entertaining the user. Narayanasamy et al [20] describe specific ways in which simulations can be differentiated from simulation games. Good examples of simulation games are The Sims ${ }^{\mathrm{TM}}$ and SimCity ${ }^{\mathrm{TM}}$.

Many simulation programs, such as simulation or modeling programs used in business, are classified as simulations but not simulation games. Additionally, some simulators, such as flight, driving, and other educational simulations, have purposes that are more functional in nature yet can also provide entertainment to the user and could therefore be classified as IDE technologies.

\subsection{Pervasive Gaming}

Pervasive gaming is the combination of digital gaming in a real-world environment in which the gaming participants play the games "unchained from the console" with the assistance of technology [21, p. 54]. This style of game has also been called "transreality gaming" [22] or "mixed reality" [23] and draws from virtual reality. An example of pervasive gaming is the human Pacman ${ }^{\mathrm{TM}}$ game in which participants utilize wearable computing, Global Positioning System (GPS) devices, and head mounted displays to physically play like they were inside a Pacman ${ }^{\mathrm{TM}}$ game [24].

\subsection{Social Networking}

Social networking involves the connections between people and interactions within social networks, which are increasingly being facilitated by the use of technology to allow people to interact while being physically separated. Social networking programs are growing in usage and functionality. Professionally, sites such as LinkedIn ${ }^{\mathrm{TM}}$ provide the ability to view the social networks of those people in your own network for business connections. Common programs such as instant messaging programs, email programs, weblogs (blogs), online communities, online photo albums, etc. can all be used for social networking. These programs allow individuals to easily meet and keep in contact with many more individuals than those that they keep in close physical proximity.

Some of the most prominent areas within online social networking include instant messaging programs and the use of personal customizable MySpace.com webpages or online blogs. Some reports have
MySpace.com receiving over 11 billion page views per month; double that of Google [25]. The use of MySpace and similar sites indicates a large trend toward the use of social networking technologies by users all over the world. While, several surveys of online messaging services found that there are about 1.3 billion registered and active instant messaging accounts in the world[26]. This makes instant messaging one of the most used technologies within both the IDE and LC technology space. In particular, blogging and instant messaging are being adopted by teenagers, who are using the tools for entertainment, research, mentoring, and other uses [27] and [28]. According the BBC in August 2005, over 14.2 million blogs were tracked by Technorati, a blog search engine, which had nearly doubled over the previous 5 months [29]. Moblogging is a recent combination of blogging from a mobile device, which highlights how some of the changes in IDE \& LC have been to integrate technologies [30].

\subsection{Wearable Computing}

Wearable computing, like virtual reality, is a field that is not as well developed or highly used by individuals for IDE or LC. A wearable computer system is a small computing device that is either attached to the body or worn as clothing-some systems operated without the use of hands [31]. Thus an $\operatorname{iPod}^{\mathrm{TM}}$ is a wearable computing device while a calculator is not. The recent development of the Bluetooth earpiece for cell phones is a good example of a lifestyle computing, wearable-computing system. This device allows a user to continue a conversation on a cell phone without the use of a hand to hold the phone to one's ear. As the processing, storage and battery power of small digital devices increase, the potential capabilities for mobile IDE \& LC devices also increase.

Lifestyle computing devices often augment the user's abilities in a certain task, but sometimes have detrimental effects. For example, McAtamney \& Parker [32] examined the detrimental effects of wearable computing on face-to-face communication.

While wearable computing devices are currently only able to do one or two precise functions well, the main goal of these devices is to seamlessly provide service to the user and become so common that the user is unaware of the boundary between the virtual and real world [33]. However, the main detriment to the widespread adoption of wearable computing is not only technical; society, in general, needs to provide acceptance of a device before the device will become commonplace and mass-produced [34]. 


\subsection{Home Automation}

Home automation is the use of technology that allows a user to interactively operate or interact with an appliance or system within a household $[35,36]$. These devices allow the owners of the home to more quickly perform many tasks efficiently and also interact with these appliances. These devices go beyond a microwave that will automatically sense the food within it and reheat it to an appropriate level without an explicit time entry by the operator. As such, they would include such technologies as: home security and surveillance; automated, personalized lighting and climate control; and control of music and media throughout the home. A home with a high level of automation may change temperature, lighting, or background music to personal preferences as a different person enters a room.

Currently, little integration of creation of personal automated networks of home devices has not extended beyond computer networks. As devices become more commonplace, easier to use, and socially accepted more homes will be classified as smart homes. Home automation is mainly limited to a few computer-based devices and in some homes, smart appliances.

\subsection{Personal electronic devices}

Personal electronic devices have influenced human productivity in many tasks other than gaming. Although this area overlaps somewhat with wearable computing, it covers devices influencing lifestyle computing that are less often worn. Devices such as the PDA are now used for many tasks previously only performed on computers. The mobility of cell phones for voice and text communication has modified how people communicate with each other. Personal navigation has changed with the use of widespread modern GPS units. Some of these devices are leading to the realization of the early theorists of ubiquitous computing, but there is much yet to be researched. Their use affects the implementation of security and privacy for computer systems. For example, Turner et al examine the implementation of a network of PDAs in a hospital, a complicated project to protect the confidentiality of patient medical records while gaining the benefits of information sharing by using the PDAs [37]. Thelander notes that personal electronic devices are becoming a great difficulty in network security [13]. How these devices affect the workplace and the lifestyles of people is an interesting avenue of research.

3. Prior Taxonomies and the IDE
Unification Framework
Given our definitions and taxonomy of personal
computing areas that relate to IDE and LC, we now

review other studies that have created taxonomies related to entertainment and gaming, which we can use to further our taxonomy of IDE. In this section, we briefly present each of these papers and the contributions that have an impact upon the IDE Unification Framework.

\subsection{Klabbers' Taxonomy}

Klabbers [38] created a taxonomy for classifying games and simulations that is based on previous gameplaying based literature, social systems theory, and the semiotic theory of gaming. Previous literature defined that the basic elements in games are actors, rules, and resources. The semiotic theory of gaming states that each of these elements is further defined by means of syntax, semantics and pragmatics. We define these last three terms and show how they affect the basic elements within games.

(1) Syntax refers to the grammatical construction of the game. Actors are members of a social group and participate in a number of roles. Actors can be a single user, multiple users, or teams. Rules define the ability to manipulate objects in the games, or what moves are available with given objects. Rules are also defined within semantics as the complete set of positions for objects within the game schema. Resources are defined as what items are available to interact with and represent objects in a real or fictitious world. These resources have an initial position, but alter position during the course of the game.

(2) Semantics refers to how a user understands the game and interacts with it. Actors are mainly seen as roles, which are defined by rules. These rules may be informal or formal, but they provide a framework to understand the actions and interactions in an actor's given role. Rules are defined as symbolic interactions between pieces within the game. The setting of the game further represents a larger social system and provides meaning to pieces that are added or altered during the course of the game. Resources are understood to represent an idea or thing in the real world.

(3) Pragmatics refers to the process of creating, playing and/or evaluating a game. Pragmatics involves establishing the syntax parameters and attaching the meaning of the semantics into one whole. Actors are defined by the goal structures of the game. Allopoetic refers to goals that are external to the game and is usually used with training programs; autopoetic refers to goals that are internal to the user while playing the game. Further, players may be viewed as a knowledge receptor by the game and the game will provide all information to the player, while the other side of the continuum is an interaction to exchange knowledge throughout the game. Rules are defined as the format 
for how the game is played and the assessment function that takes place at the end of the game. Materials refer to the physical items the player receives that are necessary to operate the game (e.g., manual, computer).

This framework combines two theories to help designers in understanding the various elements involved within the game structure. This model is more equipped and adjusted for designers as it allows them to understand what needs to be programmed and understood in the process of making the game. However, it does not provide a way to distinguish readily between games. We utilize the basic elements of games from Klabber's Taxonomy-actors, rules, and resources - in our unified taxonomy.

\subsection{Lindley's Game Classification Space}

Lindley [22] created a taxonomy that describes pervasive gaming, which he calls trans-reality gaming. Pervasive gaming is the synthesis of digitally supported games enacted or played in a real-world environment. He states that games can be categorized by several characteristics: game, narrative, simulation, fiction, or virtuality. Game is defined as a set of agreed upon rules that create a competitive activity to achieve some goal. The rules provide the framework for the player(s) to use to interact and advance through the game. Narrative is defined as a structured context provided to the user to explain the interactions of elements, characters and actions within the game. Narratives are more easily identifiable when they follow the typical three-act restorative structure, which is prevalent in novels, computer games and cinema. In this structure a conflict is created in the first act. During the second act, the conflict is further developed and explored by the user. In the third, the conflict is resolved. Simulation is defined as the use of a system to representation of the functions, operation or features of a desired system. Figure 1 summarizes how these three elements can differentiate between game types, which Lindley refers to as a Game Classification Space.

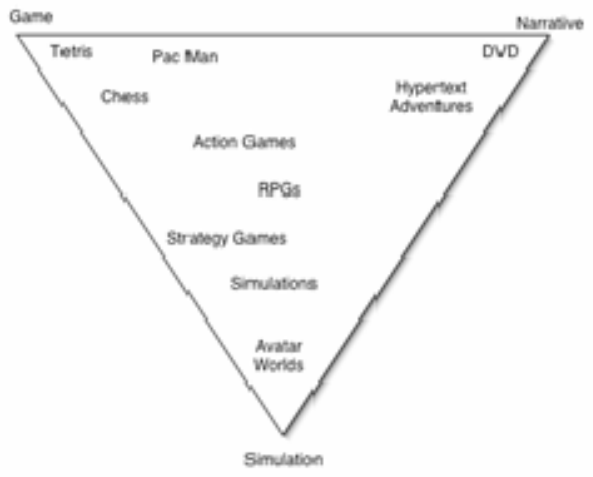

Figure 1. Game Classification Space, from [22, p. 6]
By further classifying games based on the fiction or virtuality of the game provides a fourth dimension to the above classification model. Virtuality is the continuum between the real-world and virtual worlds that can be created by a game, whereas, fiction defines the continuum between games that range from complete fabrications to complete simulation of something in the real world.

Though this taxonomy is an excellent contribution to the literature, the Game Classification Space model presented causes some difficulties when attempting to classify IDE-typed games or systems. First, as seen through some of the provided examples, these models are used to classify systems and games that are not within the IDE area. Further, the classification to divide games based upon non-fiction vs. fiction, or virtual vs. physical world settings does not help classify any real differences between games or systems besides those particular characteristics. Those classifications do not help define how users will interact with the system, or even what genre of game is involved, just where the setting of the game occurs. Third, the two-dimensional Game Classification Space does not help to define what types of game the user is enjoying, but mainly what the content of the game or how its rules define the game is played. This taxonomy also does not provide any information to develop genres or types of systems to detail the level of interactivity with other users. This taxonomy provides ways to compare specific games to another game rather than creating larger game categories. From the Game Classification space, we expand game to be entertainment experience in our taxonomy, include narrative as a category. Simulation is found to be an example of the genre component.

\subsection{Interaction-Centric Structural Framework}

Björk and Holopainen [39] created a framework called the interaction-centric structural framework to categorize games. This framework uses four components to categorize games: holistic, bounding, temporal and objective. We will describe each of these major component areas below.

(1) Holistic components are components that deal with treating the game as a whole entity and how these components relate with other activities. Holistic components consist of game instance, game session, and play session. Game instance refers to the requirement that every time that the game is played it is unique from previous instances of the game. Game session component is defined as user's activity of playing a game instance. Game session times can vary from a few minutes (e.g. MinesweeperTM), to a few 
hours (e.g. Halo $\left.{ }^{\text {TM}}\right)$, to an indefinite amount of time (e.g. EverQuest ${ }^{\mathrm{TM}}$ ). Play sessions refer to the amount of time a user spends on a game session. A game session can be completed by one or multiple play sessions by one or multiple game users.

(2) Bounding components define how to define the activity taking place and how it could be redefined. Bounding components consist of rules, modes of play, and goals and subgoals, Rules create the flow of the game by defining how aspects of the game behave and interactions of the game with the user. Modes of play are created views, abstractions, or displays to differentiate between different states or activities within the game's overall framework. An example of a mode of play is an inventory view in a role playing game, and its separation from an overhead view that shows movement of a party in the created world. Goals and subgoals are the aims of a player and require actions to complete them. Goals can be either exogenous or endogenous. Endogenous goals refer to the common goal of how to win the game, while exogenous goals refer to the external goals of the user that provides additional meaning to the game or provides additional motivation for playing.

(3) Temporal components are those that are used to save the playing of the game. These components either temporally unique activities within the complete game or distinguishes between these unique activities. Temporal components include: actions, events, closures, end conditions, and evaluation functions. Actions are performances of the user that change the state of the game. Allowable actions will change throughout the game depending on its current state of the game of the current mode of play. Actions can be continuous or discrete in regards to the game state and also include communication between different users. Events are precise moments when the player changes the game state. Closures refer to an alteration of the game state that is easily identifiable due to an understood transition upon completion of a goal or subgoal. Closures can occur due to the player giving up on a goal or by deterministic events. End conditions define the game state that must be achieved to cause a closure. End conditions are almost always paired with evaluation functions. Evaluation functions provide a framework to judge the consequences of an event. Evaluation functions usually provide a framework to decide who wins and who loses in a game.

(4) Objective components deal with concepts that describe the game without looking at the game as one large activity. Objective components include: players, interface, and game components. Players are defined as thinking entities that can perform actions, have strategies and goals, and can enter or exit the game.
Players may be manifested as an avatar or simply a name. Interface is defined as the look-and-feel that the player uses to access the game. Game components are elements within the game that inform the player about the current state of the game. Game components have attribute structures and action structures for each component. These associations provide meaning to the player within the context of the game.

All of the elements in the interaction-centric structural framework are included in our unified taxonomy.

\subsection{Caillois' Taxonomy}

Caillous [40] created a taxonomy to describe games based on their basic type and rule basis. According to this taxonomy, there are four basic types of games that can be used in creating one game: agon, alea, mimicry, and ilinx. Agon refers to games that competitive in nature, while alea type games are games of chance. Mimicry games involve role-playing or acting and ilinx refers to games that offer bodily sensations out of the ordinary. Further, games can be defined by how restrictive the rules are. Ludus refers to games that are rule-based, while, paideia refers to games that are free-form and not deeply defined by rules. Games can have different concentrations of the four game types and be on a spectrum of how rulebased or free-formed the game's rules are. This taxonomy is particularly helpful when distinguishing between particular games, but is unable to create broad distinctions between basic game genres within IDE. The elements of this taxonomy are included as part of the entertainment experience or as part of the rules category.

\subsection{Multi-dimensional Typology}

Aarseth et al. [41] provide a taxonomy to classify games that take place in a virtual world. Their taxonomy is based on spatial movement and can be used to categorize computer games, sports, or even board games. They defined thirteen dimensions under five headings: space, time, player-structure, control, and rules. We describe these areas in the paragraphs below.

(1) Space is defined how the game involves various aspects of space. Space involves the following dimensions: perspective, topography and environment.

Perspective involves how the user is able to examine the game, or the perspective of the interface. Most perspectives are first or third-person views (called vagrant view and omni-present view respectively). However, some games provide the ability to switch between these views, or provide views that are neither first nor third-person perspectives; these perspectives are referred to as isomorphic. 
Topography refers to how the game allows the movement and use of space within the gaming environment. Games that allow free movement along all directions are called geometrical, while games that define a precise number of non-overlapping positions (e.g. the 64 squares in chess) are called topological.

Environments can be either dynamic or static. If a user is able to alter aspects of the environment in the game it is called dynamic, whereas the inability to change the aspects of the environment is called static.

(2) The time area of a game involves how time is represented and used within a game. The three dimensions within time are: pace, representation and teleology. Pace involves whether a player may act independently or must act in turns with other players/adversaries. If the game allows a user to be active at all times and act independent of other users, it is called real-time. While, if the user must take turns with other players to act, it is called turn-based. Representation defines what time means within the game. If time is meant to represent real-world time, it is called mimetic. Whereas, the passing of time in a game that has no meaning is referred to as arbitrary (e.g., Tetris). Teleology refers to whether there is a defined time as to when the game can end. If a game has no clear ending point, it is called infinite (e.g., Tetris), whereas, a game with a clear ending point is called finite.

(3) Player-structure defines how players or teams interact and how the adversaries interact. Users can interact as players or teams, and then as single players/teams, two-player/two-teams, or multiplayer/multi-team levels.

(4) Control refers to the ability that the user has over the game to determine aspects of the game. Control includes the following dimensions: mutability, savability, and determinism. Mutability refers to the rewarding of user behavior through the use rewards to alter the user's position. Static mutability is the assigning of points or stating who has won or lost. Whereas, power-ups refer to temporary rewards that may be gathered, discarded or destroyed. Rewards that permanently alter the state of the character are called experience-leveling mutability. Savability refers to the user's ability to save the game state. If the game cannot be saved, it is called non-savable, whereas the ability to save at any point is unlimited. The ability to save at only specified locations or points in time is called conditional savability. Determinism refers to the randomness available in the game to determine the course of events. Non-deterministic games always display the same outcome no matter what response was elicited by the user prior to the outcome. Games where users are free to pursue any course of action and the action provides a random response, even to similar situations, is called deterministic.

(5) Rules define how the game is played. Rules involve interactions of objects within the game, with the user, and the user with the game. Aarseth [41] defined rules into three meta-categories and whether the game had these rules or not: topological, timebased and objective-based. Topological refers to rules that are determined by a player's position in the game world. If the rules are universal and apply to all locations of the game, then the rules are universal and not topological. Time-based rules are rules that significantly alter the game-state due to the passage of time. Objective-based rules alter the progress or outcome of the game based on the meeting of a specified condition.

The taxonomy created by Aarseth et al. [41] is very precise at defining individual games and comparing and contrasting them with other games. This taxonomy is fairly complex as it involves thirteen attributes along a continuum to characterize individual games. It does not attempt to create genres of games, but provides a way to compare varying elements within individual games. We include all elements of this multi-dimensional typology in our unified typology.

\subsection{IDE Unification Framework}

In Figure 2, we attempt to provide an over-arching taxonomy that consolidates all the major concepts and taxonomies presented in this paper. We call our taxonomy the "IDE Unification Framework." This framework represents a decision model of game attributes that can be used in designing IDE-based games, or in performing IDE-based research. This initial taxonomy can be used to generate more research on IDE-related topics and issues. Several areas within IDE are more heavily researched and defined as shown by the literature and amount of products within those areas. As previously discussed, this framework builds upon the work in prior taxonomies by synthesizing and expanding them. Additionally, the previous taxonomies left several gaps that we have attempted to rectify with this overall taxonomy of IDE. These gaps include: (1) Lacking a complete overview of the IDE area. No paper has attempted to define interactive digital entertainment and what type of systems this includes. (2) Not showing proposed relationships other taxonomies provide between the categorized elements (3) Inability to compare genres or types of systems rather than based on specific game attributes that alter by games within a genre. 


\section{Future Research}

Because IDE involves an emerging family of technologies and is relatively new to academic research, many opportunities for research exist. This section highlights key areas for potential research.

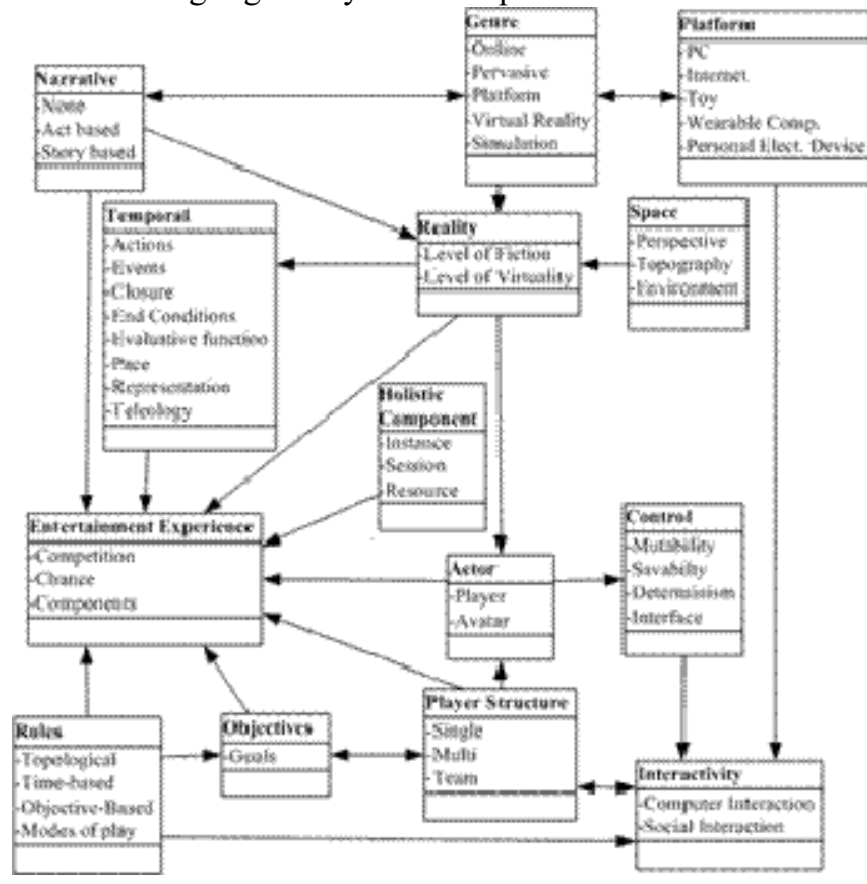

Figure 2. IDE Unification Framework

Interactive digital entertainment (IDE) systems have potential applications beyond entertaining their user(s). Educational uses of IDE have shown that children are more able to learn material through such interactive entertainment [42], including high school [43] and college-age students [44]. Psychologists have used devices to help in the therapy of individuals with intense phobias or other conditions [45]. While, several devices have been focused towards homes and providing venues for entertaining children [35].

Some forms of IDE, such as video games, provide pressure for performance improvements in hardware and software. Increasing growth of IDE and further research could potentially increase such broad areas as CPU speed, digital processing, 3D processing and imaging, new devices for $\mathrm{I} / \mathrm{O}$, practical wearable devices, improved methods of education, socialization, applications for patient therapy, group forming and stimulating, leadership training, simulation training, employment training, AI algorithms, virtual reality displays etc.

Future research can identify many concepts, relationships and assumptions that have been posited by various practitioners and researchers. Primarily, the concept that needs the most understanding is that of interactive entertainment. Some of the key questions include: What can increase or decrease interactive entertainment? What is entertaining and how can something be adapted to be more or less entertaining? What differences exist between the effects of IDE and LC on people versus non-IDE systems and devices? Beyond defining interactive entertainment through the use of conceptual model, it is critical to create related instruments for helping measure and predict entertainment.

Further research could expand upon the ramifications that IDE and LC systems have on society at large. Little is understood about the adoption of LC and IDE systems. For example, what aspects of entertainment and cause some systems to be more widely adopted than other systems? Other questions include: How has the acceptance of IDE and LC devices altered social networks, changes in education, therapy via technology, every-day life changes, increases or decreases in information overload, technology improvements, addictions to technology, advances in AI programming, infringements on intellectual property rights, and changes in the mode and behaviors of communication?

\section{Conclusion}

IDE is increasingly pervasive in computing and society in general. Already, consumers spend billions of dollars per year on IDE, and major social networks related to IDE are accelerating. However, academic research has yet to bring clarity and focus to this new area of research. Little is known about what makes one form of IDE more entertaining than another form of IDE, for a particular type of person. Also, little is known about the social effects that IDE will play on society as IDE increasingly moves into the realm of social interaction.

In this paper, we have provided a basic overview of interactive digital entertainment and computing lifestyle technologies and clarified these concepts. Further, we have provided information about how to distinguish between various subgroups within IDE by defining these areas. We have also reviewed several taxonomies that defined subgroups within IDE and synthesized these to form the IDE Unification Framework. This framework can be used to guide future research and to solidify the understanding of IDE research field. Potential research questions have also been discussed to help increase the quantity and quality of research in IDE.

\section{References}

[1] G. D. Abowd and E. D. Mynatt, "Charting past, present, and future research in ubiquitous computing," ACM Transactions on Computer-Human Interaction, vol. 7, pp. 29-58, 2000. 
[2] B. Salem and M. Rauterberg, "Aesthetics as a Key Dimension for Designing Ubiquitous Entertainment Systems," presented at 2nd International Workshop on Ubiquitous Home, Kyoto, Japan, 2005.

[3] R. Nakatsu, M. Rauterberg, and P. Vorderer, "A New Framework for Entertainment Computing: From Passive to Active Experience," presented at International Conference on Entertainment Computing, Sanda, Japan, 2005.

[4] H. van der Heijden, "User acceptance of hedonic information systems," MIS Quarterly, vol. 28, pp. 695-704, 2004.

[5] D. Wixon, "Are We Having Fun Yet? Computers as Entertainment Objects," Interactions, pp. 46,60, 2006.

[6] T. Manninen, "Rich interaction in networked virtual environments," ACM Multimedia, pp. 517-518, 2000.

[7] Y. Liu and L. J. Shrum, "What is interactivity and is it always such as good thing? Implications of definition, person, and situation for the influence of interactivity or advertising influence," Journal of Advertising, vol. 31, pp. 53-64, 2002.

[8] S. Rafaeli, "Interactivity: From new media to communication," in Advancing Communication Science: Merging Mass and Interpersonal Processes, R. Hawkins, J. Weinmann, and S. Pingree, Eds. Newbury Park, CA: Sage, 1988, pp. 110-134.

[9] P. Vorderer, C. Klimmt, and U. Ritterfeld, "Enjoyment: At the Heart of Media Entertainment," Communication Theory, vol. 14, pp. 388-408, 2004.

[10] S. A. Brown and V. Venkatesh, "Model of adoption of technology in households: A baseline model test and extension incorporating household life cycle," MIS Quarterly, vol. 29, pp. 399-426, 2005.

[11] V. Venkatesh, "Computers and other interactive technologies for the home," Communications of the ACM, vol. 39, pp. 47-52, 1995.

[12] A. Crabtree, T. Rodden, T. Hemmings, and S. Benford, "Finding a place for UbiComp in the home," presented at International Conference on Ubiquitious Computing (UbiComp), Seattle, Washington, USA, 2003.

[13] M. Thelander, "The great wall syndrome," IT Professional, vol. 7, pp. 25-30, 2005

[14] A. G. Brooks, J. Gray, G. Hoffman, A. Lockerd, H. Lee, and C. Breazeal, "Robot's play: interactive games with sociable machines," Comput. Entertain., vol. 2, pp. 10--10, 2004.

[15] G. C. Burdea and P. Coiffet, Virtual reality technology. Hoboken, NJ: John Wiley \& Sons, 2003.

[16] M. Mine, "Towards virtual reality for the masses: 10 years of research at Disney's VR studio," presented at International Immersive Technologies Workshop, 2003.

[17] A. G. Sutcliffe and K. D. Kaur, "Evaluating the usability of virtual reality user interfaces," Behavior \& Information Technology, vol. 19, pp. 415-426, 2000.

[18] J. Bywater, M.-L. Bourguet, G. Kazai, M. Lalmas, and A Pearmin, "Scalable and Personalised broadcast service," Proceedings of the European Conference on Interactive Television: Enriching the Experience, 2004.

[19] J. Freeman and J. Lessiter, "Using attitude based segmentation to better understand viewer's usability issues with digital and interactive tv," Proceedings of the European Conference on Interactive Television: from viewers to Actors?, 2003.

[20] V. Narayanasamy, K. W. Wong, C. C. Fung, and A. Depickere, "Distinguishing Simulation Games from Simulators by considering Design Characteristics," presented at Australasian Conference on Interactive Entertainment, Sydney, Australia, 2005.

[21] S. Benford, C. Magerkurth, and P. Ljungstrand, "Bridging the physical and digital in pervasive gaming," Communications of the ACM, vol. 48, pp. 54-57, 2005.

[22] C. Lindley, "Trans-reality gaming," Proceedings of the Workshop in Computer Games Design and Technology, 2004.
[23] M. Faust, "Mixed reality gaming environment QuakeRunner," 2002.

[24] A. D. Cheok, K. H. Goh, W. Liu, F. Farbiz, S. W. Fong, S. L. Teo, Y. Li, and X. Yang, "Human Pacman: a mobile, wide-area entertainment system based on physical, social, and ubiquitous computing," Personal and Ubiquitous Computing, vol. 8, pp. $78-81,2004$

[25] S. Rosenbush, "MySpace growing even faster since acquisition," in BusinessWeek online, 2005.

[26] "Instant Messaging," Link: http://en.wikipedia.org/wiki/Instant_messaging\#User_base, Last updated: 2006.

[27] R. E. Grinter and L. Palen, "Instant messaging in teen life," presented at Conputer Supported Collaborative Work (CSCW), New Orleans, Lousinana, USA, 2002.

[28] D. J. Schiano, C. P. Chen, J. Ginsberg, U. Gretarsdottir, M. Huddleston, and E. Isaacs, "Teen use of messaging media," presented at CHI, Minneapolis, Minnesota, USA, 2002.

[29] "One blog created 'every second'," in BBC News, 2005.

[30] R. Godwin-Jones, "Messaging, gaming, peer-to-peer sharing: Language learning strategies \& tools for the millenial generation," Language Learning \& Technology, vol. 9, pp. 1722, 2005.

[31] E. O. Thorp, "The invention of the first wearable computer," presented at International Symposium on Wearable Computers, 1998.

[32] G. McAtamney and C. Parker, "An examination of the effects of a wearble display on informal face-to-face communication," presented at CHI, Montreal, Quebec, Canada, 2006.

[33] H. Cristol, "The future of wearable computers," The Futurist, pp. $68-69,2002$.

[34] C. Edwards, "Wearable computing struggles for social acceptance," IEE Review, vol. 49, pp. 24-25, 2003.

[35] M. Kirchhof and S. Linz, "Component-based development of Web-enabled eHome services," Personal and Ubiquitous Computing, vol. 9, pp. 323-332, 2005

[36] M. J. DeMaria, "Home smart home," Computing, vol. 13, pp. $55-60,2002$

[37] P. Turner, G. Milne, M. Kubitscheck, I. Penman, and S. Turner, "Implementing a wireless network of PDAs in a hospital setting," Personal and Ubituitious Computing, vol. 9, pp. 204217,2005

[38] J. H. G. Klabbers, "The gaming landscape: A taxonomy for classifying games and simulations," presented at Level Up Digital Games Research Conference, Utrecht, The Netherlands, 2003.

[39] S. Björk and J. Holopainen, "Describing Games an InteractionCentric Structural Framework," presented at Digital Games Research Conference, Utrecht, The Netherlands, 2003.

[40] R. Caillois, Man, Play, and Games. New York, New York, USA: The Free Press of Glencoe, 1961.

[41] E. Aarseth, S. M. Smedstad, and L. Sunnana, "A multidimensional typology of games," presented at Digital Games Research Conference, Utrecht, Netherlands, 2003.

[42] T. H. Egloff, "Edutainment: a case study of interactive cd-rom playsets," Computers in Entertainment, vol. 2, pp. 13, 2004.

[43] M. Kavakli, B. Akca, and J. Thorne, "The role of computer games in the education of history," 2004.

[44] S. Goschnick and S. Balbo, "Game-first Programming for Information Systems Students," presented at Second Australasia Conference on Interactive Entertainment, Sydney, Australia.

[45] A. Frank and N. Lundblad, "The new role of gaming: How games move outside entertainment," presented at International Workshop on Entertainment Computing 2002, 2002. 